Z. klin. Chem. u. klin. Biochem.

7. Jg., S. 14-17, Januar 1969

\title{
Die Blutzuckerbestimmung mit der $o$-Toluidin-Methode ohne Eisessig
}

\author{
Von A. Härtel, R. Helger und H. LANG \\ Aus der Biochemischen Abteilung der E. Merck AG, Darmstadt
}

(Eingegangen am 6. August 1968)

Bei der Blutzuckerbestimmung mit o-Toluidin bietet die Verwendung eines Gemisches aus Glycolsäure und Äthylenglycolmonomethyläther anstelle von Eisessig folgende Vorteile: keine Gerucbsbelästigung, höhere Farbausbeute. Die nach der neuen Variante ethaltenen Glucosewerte stimmen sehr gut mit denen der bisherigen Methode überein, so daß die Anwendung des eisessigfreien o-Toluidin-Reagenzes zur Blutzuckerbestimmung im Kliniklaboratorium empfohlen werden kann.

\section{The determination of blood sugar by the o-toluidine metbod without glacial acetic acid}

In the determination of blood sugar with o-toluidine, a mixture of glycollic acid and ethyleneglycol-monomethyl ether has the following advantages as a replacement for the glacial acetic acid: no irritant vapour, higher colour yield. The glucose values obtained with the modified method are in good agreement with those obtained by the former method. The use of the new o-toluidine reagent without glacial acetic acid is recommended for the determination of blood sugar in the clinical laboratory.

Die Blutzuckerbestimmung mit o-Toluidin $(1,2)$ gehört seit einigen Jahren wegen der Spezifität, der geringen Störanfälligkeit und der einfachen Durchführung $\mathrm{zu}$ den Standard-Methoden der klinischen Laboratorien. Allerdings besitzt sie im Vergleich zur enzymatischen, Blutzuckerbestimmung einen Nachteil: Durch die Verwendung von Eisessig als Lösungsmittel kommt es fast bei allen Schritten der Analyse (z. B. beim Pipettieren des Reagenzes, bei der Durchführung der Farbreaktion im siedenden Wasserbad, beim Messen am Photometer) und beim Reinigen der Gefäße zu einer Geruchsbelästigung. Wenn pro Tag einige Hundert Analysen durchgeführt werden, was in größeren Kliniken häufig vorkommt, wird der Essigsäuredampf zum ernsten Problem.

Man hat versucht, durch Verwendung von 50proz. Essigsäure diesen Nachteil zu verringern (3). Dabei mußte jedoch eine längere Reaktionszeit und eine geringere Farbausbeute in Kauf genommen werden (siehe Abb. 1), so daß sich das Verfahren in der Praxis nicht durchsetzen konnte. Aus diesem Grund wurde nach Möglichkeiten gesucht, die Blutzuckerbestimmung mit Hilfe der 0 -Toluidin-Methode ohne Eisessig durchzuführen.

\section{Untersuchungen über die o-Toluidin-Methode}

Glucose bildet mit $o$-Toluidin in Eisessig in der Hitze einen grünen Farbstoff. Die Lösung besitzt je ein Extinktionsmaximum bei $380 \mathrm{~nm}$, bei $480 \mathrm{~nm}$ und bei $620 \mathrm{~nm}$. Während Ketosen unter den gleichen Reaktionsbedingungen ebenfalls eine Absorption im nahen UV-Bereich und Pentosen ein Extinktionsmaximum bei $480 \mathrm{~nm}$ ergeben, ist das $620 \mathrm{~nm}$-Maximum für Aldohexosen spezifisch. Anstelle von o-Toluidin können auch andere aromatische Amine mit einer freien und einer Alkyl-substituierten, $o$-Stellung verwendet werden (z. B. 2,3- oder 2,4- oder 2,5-Xylidin). Dagegen bilden Anilin, $m$ - und $p$-Toluidin sowie 3,4-, 3,5- und 2,6-Xylidin und viele andere aromatische
Amine mit Aldohexosen nur das unspezifische Maximum im UV-Bereich. Auch hinsichtlich der Störbarkeit durch andere Verbindungen bestehen große Unterschiede zwischen der Anilin-Methode $(380 \mathrm{~nm})$ und der $o$-Toluidin-Methode $(620 \mathrm{~nm})(z$. B. wird durch Mineralsäuren die Ausbildung des $620 \mathrm{~nm}$-Maximums verhindert, während die des UV-Maximums verstärkt wird). Aus diesen Gründen beschränken sich die nachfolgenden Untersuchungen nur auf das „AÝdohexose-spezifische" Maximum und sind nicht immer auf das sogenannte Anilin-Eisessig-Verfahren anwendbar,

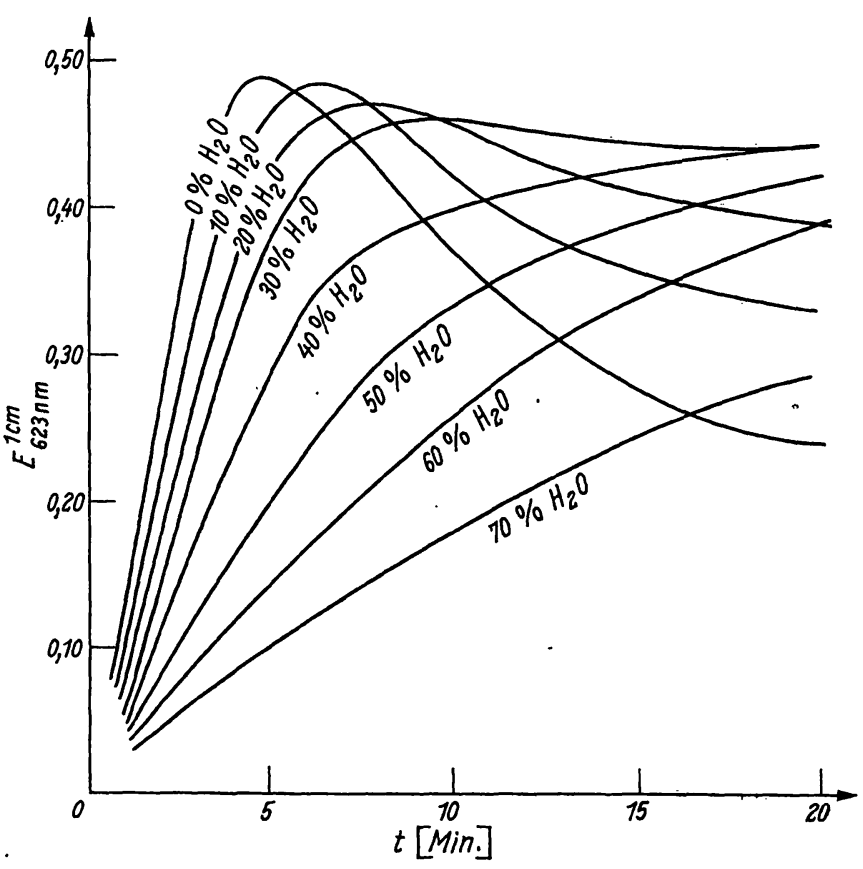

Abb. 1

o-Toluidin-Methode mit Eisessig:
Farbentwicklung in Abhängigkeit von der Zeit für verschiedene Wassergehalte im Reaktionsgemisch

Reagenz: $10 \mathrm{ml}$ o-Toluidin

$100 \mathrm{ml}$ Eisessig-Wasser-Gemisch

Analyse: $\quad 0,4 \mathrm{~g} l$ Thioharnstoff $2 \mathrm{ml}$ Reagenz

1) wasserfreie Glucose 
obwohl dieses Verfahren manchmal als Varinnte der o-Toluidin-Methode angeschen wird.

Es empfichlt sich nicht, den Eisessig durch die üblichen Säuren zu crsetzen. In Fulle der aliphatischen Monocarbonshiuren ist die Gcruchsbelästigung »u stark bzw. dic Löslichkeit im wäßrigen Medium au gering. Dic Dicarbonsäuren sind fest und auch mit den in Frage kommenden Lösungsverinittlern nicht in ausreichender Konzentration in I.ösung zu bekommen. Außerdem treten mit o-']'oluidin häufig Ausfällungen auf. Bel Verwendung von Halogenfettsäuren oder Thiosäuren oder anorganischen Säuren crhält man keine bzw.. nur äußerst geringe Farbausbeuten.

Ferner verhindert der Ersat\% des Eisessigs durch organische lüsungsmittel dic Bntstchung des Farbstoffes.

Dagegen ist es möglich, den Eisessig vollständig durch cinc Lösung von Hydroxycarbonsäuren in hydroxylgruppenhaltigen organischen Lösungsmitteln zu ersetzen. Dieses Reaktionsmedium bewirkt im Gegensatz zum Eiscssigrcageň keine Geruchsbelästigung. Es licfert darüber hinaus bei gecigneter Wahl der Reaktionsbedingungen sogar höhcre Farbausbeuten.

lïur dic Verwendung der im reinen Zustand kristallinen Hydroxycarbonsäuren sind Lösungsvermittler notwendig. Dic genannten hydroxylgruppen-haltigen organischen Lösungsmittel sind hicrfür bestens geeignet, cla sie dic Farbreaktion nicht bzw. kaum stören. Wegen der höheren Sicdepunkte werden Propanol und Äthylenglycolmonomethyläther bevorzugt. Es ist vorteilhaft, die Säure so wcit wie möglich durch das Lösungsmittel zu ersetzen, da hicrdurch dic Viskosität der Reaktionslösung ernicdrigt wird. Bei zu geringer Säurekonzentration sind jecloch die Reaktionszeiten zu lang und die Farbausbeuten zu klein: optimal ist eine Konzentration

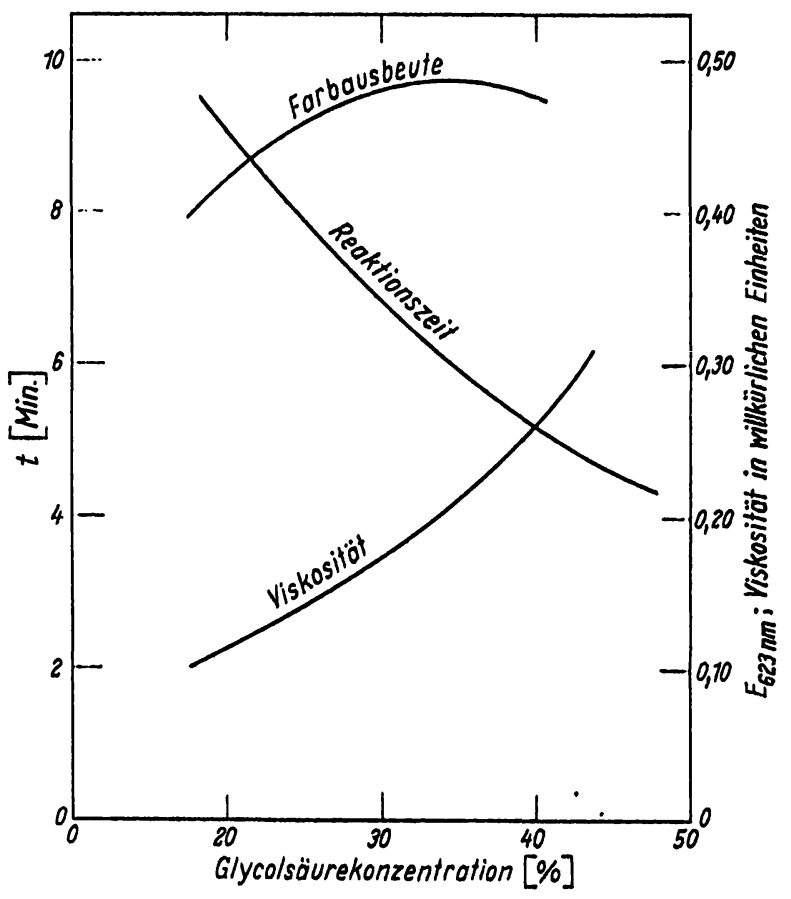

Abb. 2

Elnfluß der Olycolsaurekonzentration auf die optimale Reaktlonszelt, auf dic Farbausbeute und auf dle Viskosität der Reagenzlosungen Reagenz: $1,0 \mathrm{ml}$ o-Toluldin

$9 \mathrm{ml}$ Olycolsture-Athylenglycolmonomethylather-

$10 \mathrm{mg}$ Thloharnstoff Analyse: $0,2 \mathrm{ml}$ Olucose-Standard $(20 \mathrm{mg} / 100 \mathrm{ml})$ von $20-35 \%$. (sichc Abb. 2). Zur weiteren Erniedrigung der Viskosität und zur Verringerung der Gclbfärbung des Reagenzes kann man schlicßlich noch einc geringe Menge Methanol zusetzen, wobei während der kurzen Erhitzungszeit bei Gehalten unter 10\% knum Verdunstungsverluste zu befürchten sind (siche Abb. 3).

Von den Hydroxycarbonsäuren sind Glycolsäure und Milchsäure am besten gecignct, da sic aus den handelsüblichen technischen Lösungen in der erforderlichen Reinheit durch mehrfaches Umkristallisicren bzw. durch Hochvakuum-Destillation hergestellt werden können.

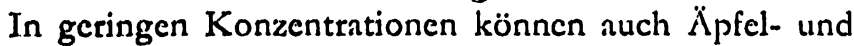
Weinsäure für die Blutzuckerbestimmung verwendet werden. Die Verwendung von Citronensäure bedingt oft Nachtcile, da die handelsüblichen Produkte Spuren von Aldosen enthalten, die sich nur schwer abtrennen lassen. Außerdem ist dic Viskosität der I.ösungen relativ hoch, so daß Schlieren in der Meßküvette sich nicht genügend ausgleichen und Fehler verursachen können.

Wie bei der Verwendung von Eisessig sind auch bei Verwendung von Hydroxycarbonsäuren die Geschwindigkeit der Farbbildung und die Farbausbeute stark vom Wassergchalt der Renktionslösung abhängig. Ohne Wasser bildet sich der grüne Farbstoff verhältnismäßig schnell. Er ist abcr auch relativ unbeständig, so daß dic Erhitzungszeit genau eingehalten werden muß. Dagegen entsteht der Farbstoff in Gegenwart von wenig Wasser langsamer, er ist aber auch in der Hitze stabiler. Bei Wassergchalten über $30 \%$ ist die Farbbildung für cine Routine-Blutzuckerbestimmung bercits zu langsam.

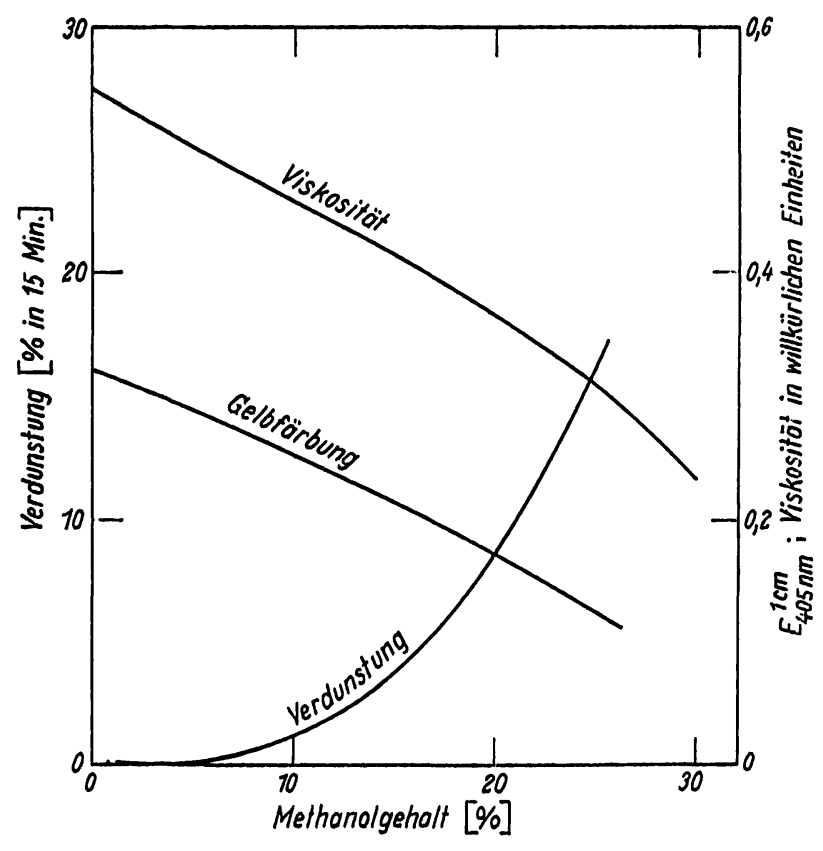

Abb. 3

Binfluß des Methanol-Oehaltes auf die Viskositat, auf dle Oclbfäbung und auf die Verdunstungsverluste des Reagenzes im sieclenden

$$
\begin{aligned}
& \text { Reagenz: } 3,0 \mathrm{~g} \text { Olycolsture } \\
& 1 \mathrm{ml} \text { o-Toluldin } \\
& 6 \mathrm{ml} \text { Methanol-Xtliylenglycolmonomethyla ther- }
\end{aligned}
$$


Die Konzentration des aromatischen Amins, z. B. des o-Toluidins, beeinflußt die Farbausbeute und die Beständigkeit des gebildeten Farbstoffes (siehe Abb. 4). Wegen der Zunahme der Zersetzungsgeschwindigkeit bei höherer 0 -Toluidin-Konzentration empfiehlt es sich, unter Verzicht auf maximale Farbausbeute bei einer Konzentration von etwa $6 \%$ o-Toluidin zu arbeiten.

Die Ergebnisse der Versuche zur Ermittlung optimaler Reaktionsbedingungen, die nach den Kriterien Geschwindigkeit der Farbbildung, Farbausbeute und Konstanz der Farbe beurteilt werden, sind in den Abbildungen 2-5 für das Beispiel Wasser/Glycolsäure/ Äthylenglycolmonomethyläther dargestellt. Bei Verwendung anderer Hydroxysäuren bzw. hydroxylgrup-

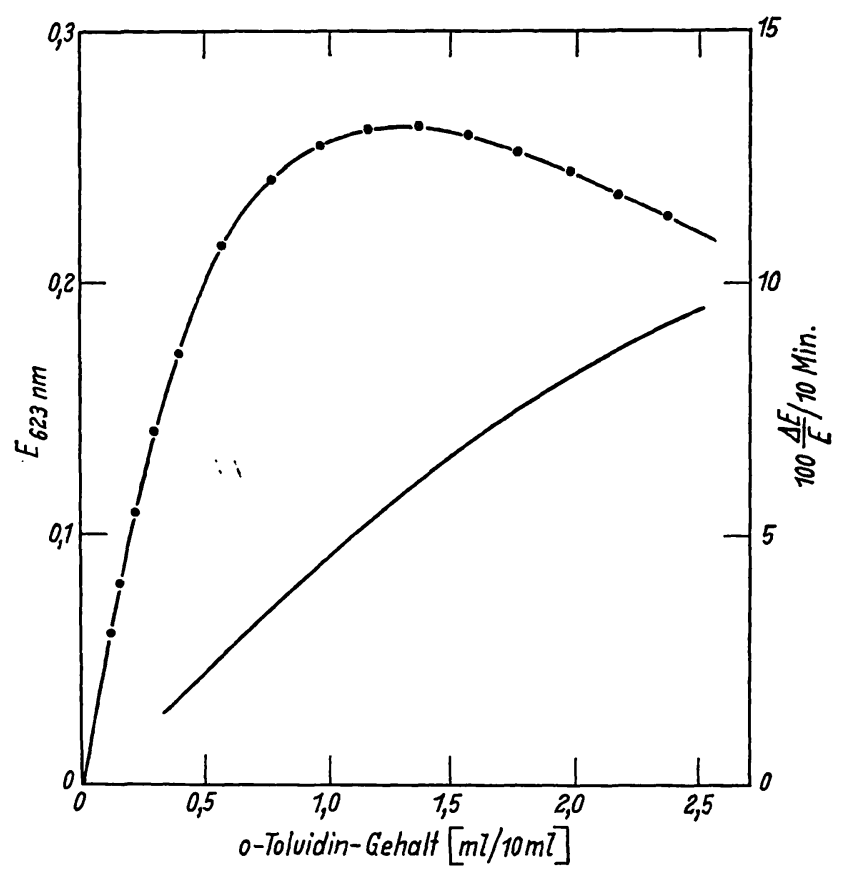

Abb. 4

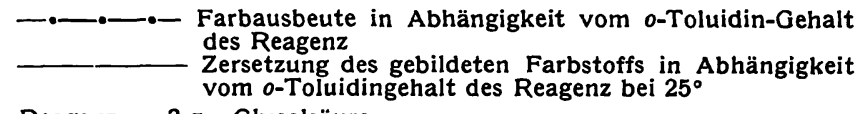

Reagenz: $\quad 3 \mathrm{~g}$ Glycolsäure

$10 \mathrm{mg}$ Thioharnstoff

Analyse: $0,2 \mathrm{ml}$ Gemisch

$0,2 \mathrm{ml}$ Glucose-Standard $\left.(10 \mathrm{mg} / 100 \mathrm{ml})^{2}\right)$
Reagenz

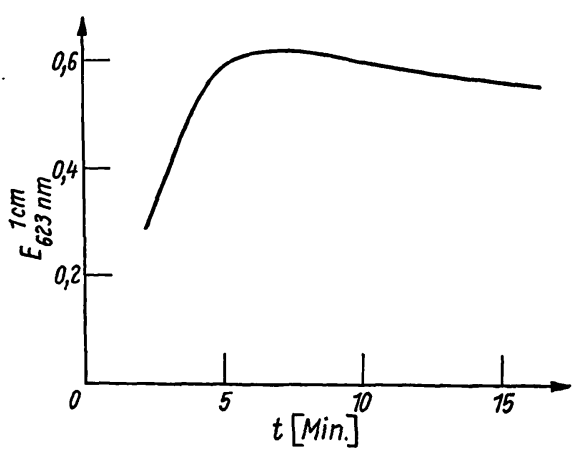

Abb. 5

o-Toluidin-Methode ohne Eisessig

Farbentwicklung in Abhängigkeit von der Erhitzungszeit

Reagenz: $1,0 \mathrm{ml}$ o-Toluidin

$0,5 \mathrm{ml}$ Methanol

$1,5 \mathrm{~g}$ Glycolsäure

$1,5 \mathrm{~g}$ Ápfelsäure

$5,5 \mathrm{ml}$ Åthylenglycolmonomethyläther penhaltiger Lösungsmittel bzw. Amine erhält man ähnliche Zusammenhänge zwischen den einzelnen Parametern; die Farbausbeuten sind jedoch meist etwas geringer und die Maxima häufig etwas verschoben. Optimal ist ein Reaktionsgemisch, das aus 1 Teil oToluidin, 0,01 Teilen Thioharnstoff, 1,5'Teilen Wasser, 4,5 Teilen Äthylenglycolmonomethyläther, 1 Teil Methanol, 1,2 Teilen. Glycolsäure und 1,2 Teilen Äpfelsäure besteht. Da die Farbausbeute fast doppelt so hoch wie bei der Verwendung des üblichen o-Toluidin-Eisessig-Reagenzes ist, kann man ein kleineres Volumen des eiweißfreien Uberstandes $(0,2 \mathrm{~m} l$ Überstand anstelle von $0,4 \mathrm{~m} l$ pro $2 \mathrm{~m} l$ Reagenz) zur Analyse verwenden.

\section{Methodik $\left.{ }^{2}\right)$}

1. Glucosebestimmung in Vollblut, Serum oder Plasma Farbreagenz

$12 \mathrm{~g}$ Glycolsäure, $12 \mathrm{~g}$ Åpfelsäure, $100 \mathrm{mg}$ Thioharnstoff, $5 \mathrm{ml}$ Wasser, $10 \mathrm{~m} l$ Methanol und $10 \mathrm{ml}$ o-Toluidin werden in $45 \mathrm{~m} l$ Äthylenglycolmonomethyläther gelöst. Bei Raumtemperatur etwa 1 Jahr haltbar.

Enteiweißungslösung

$5 \mathrm{~g}$ Trichloressigsäure in $100 \mathrm{~m} l$ Wasser lösen.

Standardlösung

$100 \mathrm{mg}$ wasserfreie Glucose in $100 \mathrm{ml}$ 0,15proz. wäßr. Benzoesäurelösung auflösen.

Ausfiibrung

$\mathrm{Zu}$ jeder Analysenserie werden nur eine Blind- und ein bis zwei Standardproben angesetzt.

A) Enteiweißung: In Zentrifugengläser einpipettieren:

\begin{tabular}{lccc}
\hline & Analyse & Standard & Blindprobe \\
\hline $\begin{array}{l}\text { Enteiweißungslösung } \\
\text { Vollblut bzW. andere }\end{array}$ & $1,0 \mathrm{ml}$ & $1,0 \mathrm{ml}$ & - \\
Kôrperflüssigkeit & $0,1 \mathrm{ml}$ & - & - \\
Standardlösung & - & $0,1 \mathrm{ml}$ & - \\
\hline
\end{tabular}

mischen, Analysenprobe 5 Min. lang zentrifugieren

B) Farbreaktion: In Reagenzgläser einpipettieren:

\begin{tabular}{|c|c|c|c|}
\hline & Analyse & Standard & Blindprobe \\
\hline $\begin{array}{l}\text { Eiweißfreier Uberstand } \\
\text { Standardgemisch } \\
\text { Enteiweißungslösung } \\
\text { Farbreagenz }\end{array}$ & $\begin{array}{l}0,2 \mathrm{~m} l \\
2, \overline{0} \mathrm{~m} l\end{array}$ & $\begin{array}{l}0, \overline{2} \mathrm{ml} \\
2, \overline{0} \mathrm{ml}\end{array}$ & $\begin{array}{l}\overline{\overline{0}} \mathrm{~m} l \\
2,0 \mathrm{ml}\end{array}$ \\
\hline
\end{tabular}

Mischen, 5-6 Min. lang in ein siedendes Wasserbad und dann sofort in kaltes Wasser stellen.

Nach dem Abkühlen die Extinktionen der Analysen= und der Standardprobe gegen die Blindlösung möglichst kurz hintereinander messen.

Extinktionsmaximum: $625-630 \mathrm{~nm}$

Filter: $\quad$ zwischen 575 und $650 \mathrm{~nm} \mathrm{z.} \mathrm{B.} \mathrm{Hg} \mathrm{578;}$

Schichtdicke: $\quad 1 \mathrm{~cm}$.

Berecbnung:

$$
\text { Glucosegehalt }=\frac{E_{\text {Analyse }}}{E_{\text {Standard }}} \cdot 100(\mathrm{mg} / 100 \mathrm{ml}) .
$$

2) Diese Methode ist demnächst als Merckotest-Reagenziensatz erhältlich. 
BEHRINGWERKE AG

MA HEURG.LAHN

Podehing

\section{Immundiffusionsplatten}

Partigen

Antiscrum-haltige Agargelplatten Behringwerke für quantitative

Plasmaprotein-Bestimmungen

B 63005

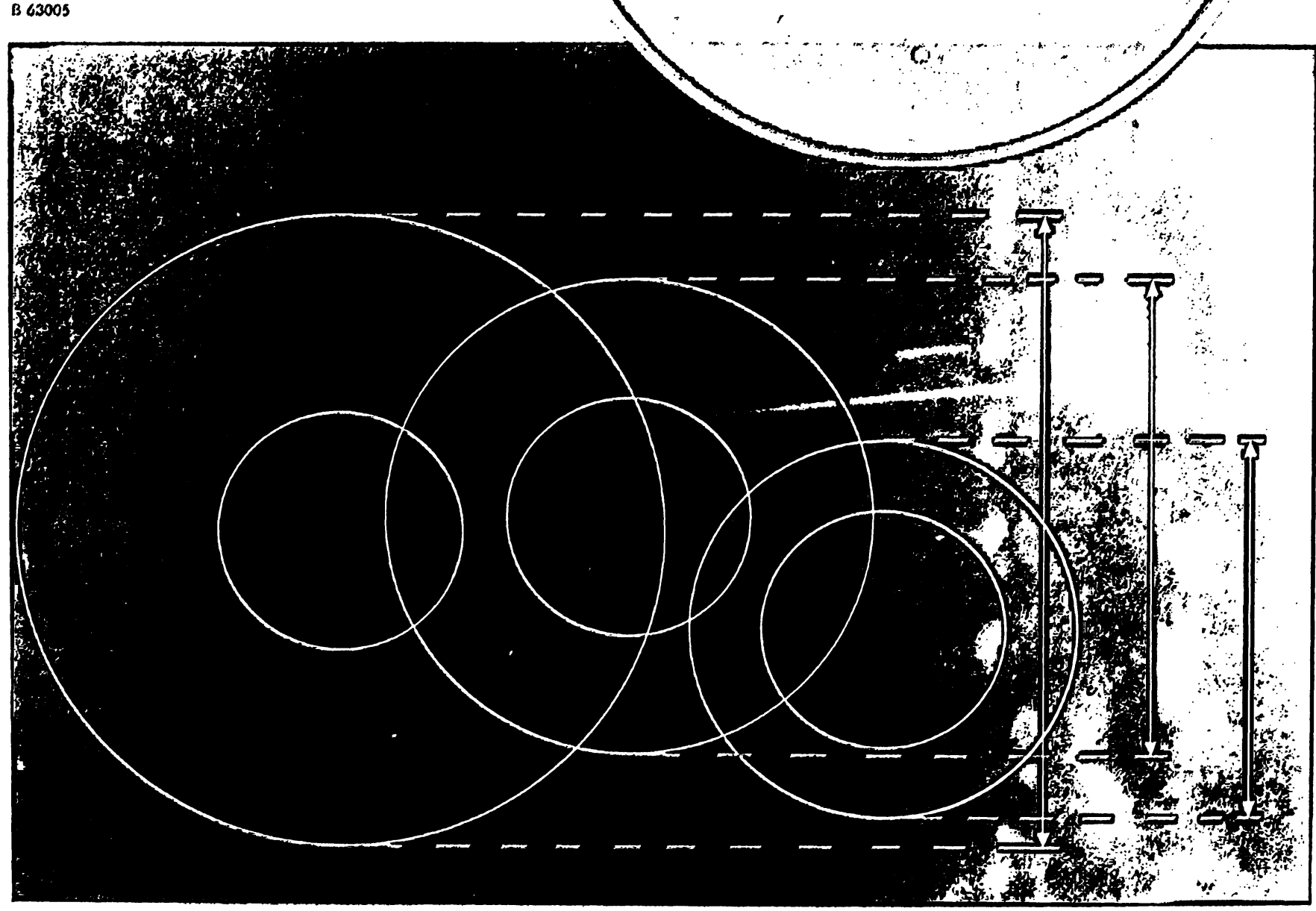


In Kïrze erscbeint

G. EBer

\section{Pfortaderhochdruck und Eiweißstoffwechsel}

Indikation und metabolische Konsequenzen porto-kavaler Anastomosen

bei Leberzirrhosekranken

Von Priv.-Doz. Dr. med. Gregor Eßer

Chirurgische Universitäts-Klinik und Poliklinik Bonn (Direktor: o. Prof. Dr. A. Gütgemann)

Mit 49 Abbildungen. Oktav. XII, 190 Seiten. 1969. Plastik flexibel DM 36,-

In der ganzen Welt steigen die Krankheiten der Leber an. Die Hepatitis steht mit an der Spitze der Infektionskrankheiten. In der Bundesrepublik übertreffen Leberschäden die Frequenz der Tuberkulosefälle. Die Anzahl der Leberkranken entspricht annähernd der der Zuckerkranken.

Die vorliegende Arbeit wurde in der Absicht geschrieben, anhand der Erfahrungen an einem einheitlichen großen Krankengut sowie aufgrund tierexperimenteller Studien eine allgemeine sowie spezielle Orientierung über Indikationsgrenzen und Behandlungsprobleme der porto-kavalen Anastomose bei Leberzirrhosekranken mit Pfortaderhochdruck zu geben. Es war Bestreben des Autors, sowohl dem am Problemkreis der portalen Hypertension besonders interessierten Kliniker und Wissenschaftler äls auch dem Allgemeinpraktiker einen Einblick in die Pathophysiologie des Pfortaderhochdrucks und der Pfortaderchirurgie zu vermitteln. Glèichzeitig aber sollte diese Arbeit den in der Praxis tätigen Hausärzten und Fachärzten eine Hilfe für die Aụslese operativ zu behandelnder blutungsgefährdeter Leberzirrhosekranker und in der postoperativen Weiterbehandlung dieser Patienten sein.

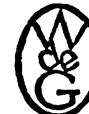

WALTER DE GRUYTER \& CO - BERLIN 30

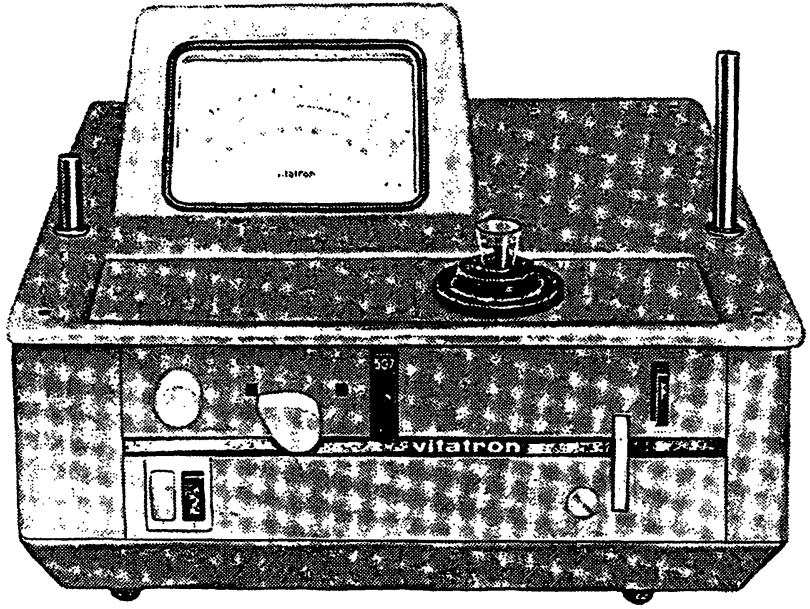

Es hat die Stabilität und Linearität eines

Doppel-Strahl Monochromator-Gerätes, kostet aber weniger als die Hälfte.

Wir können Ihnen hier nicht all seine Vorzüge beschreiben. Aber wenn Sie in Ihrem Labor ein wenig Platz übrig haben (nur $32 \mathrm{~cm} \times 32 \mathrm{~cm}$ ),

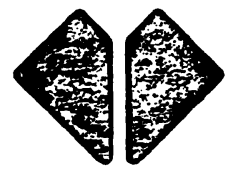

vitatron
Wir sind sicher:

Das VITATRON UC 200 PRÄZISIONS-COLORIMETER ist eines der stabilsten Ein-Strahl-Photometer der Welt.

dann führen wir es Ihnen gern vor.

Sollten Sie noch etwas meht Platz haben

$(30 \mathrm{~cm} \times 43 \mathrm{~cm})$, dann bringen wir auch unseren VITATRON-DIGITALWANDLER mit. Er druckt automatisch die Photometeranzeige als Konzentration oder Extinktion aus, zusammen mit der Proben-Nummer.

Fordern Sie bitte weitere Informationen an! Unsere Service=Station ist in Ihrer Nähe. 


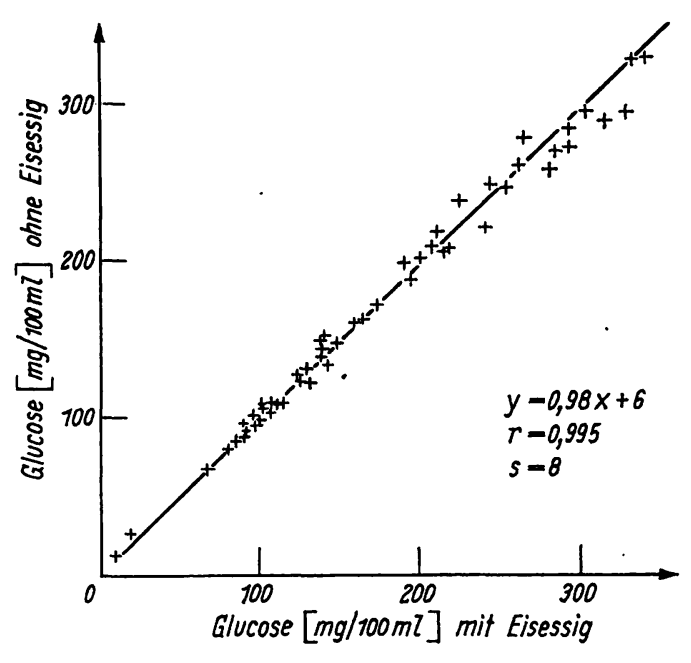

Abb. 6

Vergleich der 0 -Toluidin-Methode mit Eisessig (Merckostest) mit oder ohne Eisessig Glucose-Bestimmung im Serum

2. Glucosebestimmung im Liquor und im Urin Anmerkung:

Die Anwendung dieser Methode setzt voraus, daß das Volumen von $0,02 \mathrm{ml}$ sehr genau pipettiert wird. Falls keine geeigneten Pipetten zur Verfügung stehen, wird der Urin, bzw. der Liquor nach der fü Vollblut bzw. Serum angegebenen Vorschrift untersucht. Unter Ver-
zicht auf Genauigkeit kann aber auch im Serum und Plasma der zicht auf Genauigkeit kann aber auch im Serum und Plasm

\section{Verdünntes Farbreagenz}

10 Teile des oben beschriebenen Farbreagenzes werden mit 1 Teil Wasser verdünnt.

Ausfiibrung:

$\mathrm{Zu}$ jeder Analysenserie werden nur eine Blind- und 1-2 Standardproben angesetzt.

In Reagenzgläser pipettieren:

\begin{tabular}{lccc}
\hline & Analyse & Standard & Blindprobe \\
\hline Liquor bzw. Urin & $0,02 \mathrm{ml}$ & $\overline{0}-\overline{\mathrm{ml}}$ & - \\
Standardlösung & $2, \overline{\mathrm{ml} l}$ & $\mathbf{2 , 0 \mathrm { ml }}$ & $2, \overline{\mathrm{ml}}$ \\
Verdünntes Farbreagenz & &
\end{tabular}

mischen, 5-6 Min. lang in ein siedendes Wasserbad und dann sofórt in kaltes Wasser stellen. Nach dem Abkühlen die Extinktionen der Analysen- und Standardlösungen gegen die Blindlösung möglichst kurz hintereinander messen. Bèi Extinktionen über 1,5 $0,5 \mathrm{~cm}-K$ üReagenz verdünnen, messen und das Ergebnis mit 5 multiplizieren.

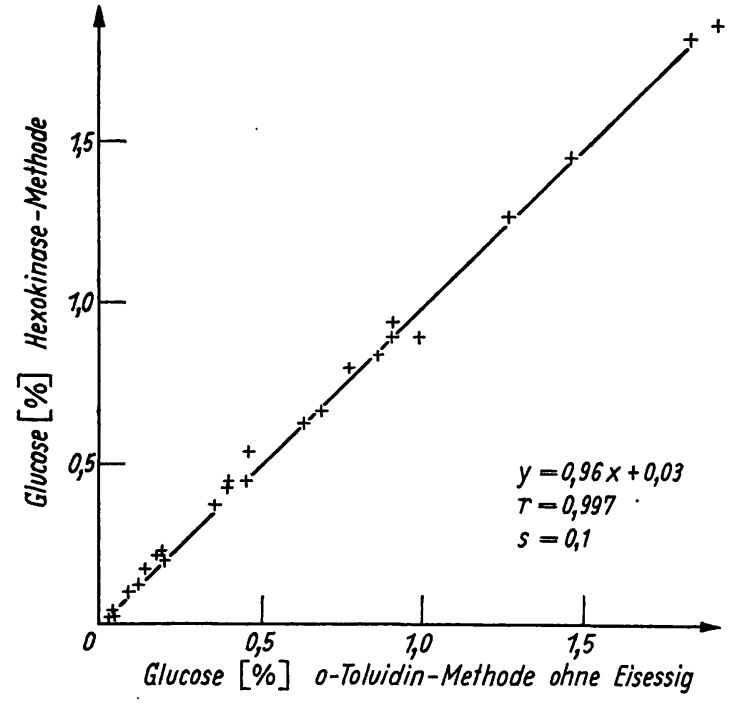

Abb. 7

Vergleich der o-Toluidin-Methode (ohne Eisessig) mit der HexokinaseMethode

Glucose-Bestimmung in Diabetiker-Urinen

\section{Ergebnisse}

Die Brauchbarkeit der neuen Methode zeigt sich bei Paralleluntersuchungen von eiweißfreien Überständen und von Urinproben mit der alten und der neuen o-Toluidin-Methode und der Hexokinase-Methode. Die Ergebnisse sind für die mittleren Konzentrationsbereiche in den Abbildungen 6 und 7 dargestellt. Man findet keine signifikanten Unterschiede in den gemessenen GlucoseWerten. Wegen der genannten Vorteile (keine Geruchsbelästigung, größere Empfindlichkeit) ist die neue $\mathrm{Va}$ riante der alten o-Toluidin-Eisessig-Methode jedoch eindeutig überlegen.

Wir danken Fräulein R. Finkenauer, Frau A. Hrmsel, Fräulein H. Kohrschürter und Frau E. Atanasova für die Durchführung der Versuche.

\section{Literatur}

1. Hultmann, E., Nature Ĺondon 183, 108 (1953). - 2. Hrvärnnen, A. und E. A. Nikkidiä, Clin. chim. Acta Amsterdam 7, 140 (1962). - 3. BRAUN, H., Arzt. Lab. 13, 177 (1967.

Dr. A. Härtel

E. Merck AG

Biochemische Abteilung

61 Darmstadt 2, Postfach 4119 